\title{
O PAPEL DA T.I NA GESTÃO DO CONHECIMENTO: ESTUDO DE CASO EM UMA AGÊNCIA DE VIAGENS EM NATAL/RN
}

\author{
${ }^{1}$ Danielle de A. Rodrigues Smilay \\ 2 Leilianne M. Trindade Barreto \\ ${ }^{3}$ Catiane Lopes Lima
}

\section{RESUMO}

A Gestão do conhecimento atrelada as Tecnologias da Informação no mercado atual cada vez mais disputado e exigente podem representar sinônimos de vantagem competitiva, mas para tal é necessário que a gestão estratégica de pessoas atue nos processos de participação dos colaboradores. Partindo da ideia de que o conhecimento surge dos indivíduos inicialmente, o objetivo dessa pesquisa é analisar como acontecem as conversões de conhecimento dentro de uma organização de serviços turísticos por meio das tecnologias da informação, utilizando-se como base o modelo da Espiral do Conhecimento de Takeuchi e Nonaka. Aplicouse um questionário junto aos colaboradores de uma franquia de agências de viagens em Natal/RN, com questões moldadas aos processos conceituais da Espiral do Conhecimento. Como resultado foi constatada a participação de ferramentas de T.I. nos processos de conversão de Socialização e Internalização de maneira mais acentuada que nos processos de Combinação e Externalização, mas que ainda há um molde voltado às ferramentas tradicionais de comunicação.

Palavras-chave: Gestão do Conhecimento. Espiral do Conhecimento. Tecnologia da Informação.

\section{THE ROLE OF I.T IN THE CONTEXT OF KNOWLEDGE SPIRAL: CASE STUDY OF A TRAVEL AGENCY IN NATAL - RN}

\begin{abstract}
Knowledge connected to Information Technologies in the current demanding and disputed market is synonymous with competitive advantage, but this requires that the strategic people management acts in participation processes of employees. It was based on the idea that initially, knowledge arises from individuals, this research has the objective to analyze the conversions of knowledge within an travel agency through Information Technologies used, and it was used the model of Knowledge Spiral of Takeuchi e Nonaka. It was applied a questionnaire with employees of a travel agency's franchise in Natal / RN, with molded questions based on the conceptual processes of Knowledge Spiral. As a result it was found the participation of tool's IT in Socialization and Internalization conversion processes more highlighted than in Combination and Externalization conversion processes, however there is still a trend turn to traditional communication tools.
\end{abstract}

Keywords: Knowledge Management. Knowledge Spiral. Information Technology.

\footnotetext{
${ }^{1}$ Mestre em Turismo pela Universidade Federal do Rio Grande do Norte - UFRN, Natal, Rio Grande do Norte, (Brasil). Experiência de Mercado e Docência nas Áreas de Turismo, Marketing e Inglês. E-mail: dani smilay@hotmail.com ${ }^{2}$ Doutora em Administração pela Faculdade de Economia, Administração e Contabilidade da Universidade de São Paulo FEA/USP, São Paulo, Brasil. Professora do Departamento de Turismo da Universidade Federal do Rio Grande do Norte - UFRN, Natal, Rio Grande do Norte, (Brasil) E-mail: leiliannebarreto@ hotmail.com

${ }^{3}$ Mestre em Turismo pela Universidade Federal do Rio Grande do Norte - UFRN, Natal, Rio Grande do Norte, (Brasil). Pesquisadora Voluntária do Conselho Nacional de Desenvolvimento Científico e Tecnológico (CNPQ) no Grupo de Estudos em Gestão do Turismo. E-mail: catianelopeslima@hotmail.com
} 


\section{INTRODUÇÃO}

As organizações estão inseridas em um mercado competitivo, que demanda profissionais mais qualificados de acordo com o perfil organizacional, que possam agregar valor aos serviços e produtos oferecidos, cabendo à Gestão Estratégica de Pessoas a responsabilidade de captar os talentos e administrá-los. O conhecimento é uma peça chave nesse contexto, pois na "sociedade do conhecimento" é preciso administrar os ativos intelectuais para que uma empresa sobreviva e possa competir (Probst, Raub \& Romhardt, 2002).

Conhecimento hoje significa lucro, em função da atual sociedade em rede oriunda do mundo globalizado, que dá cada vez mais importância e valor à informação e ao conhecimento que é gerado a partir dela (Castells, 1999). Logo, quanto mais se detém conhecimento, mais se tem poder de lucratividade no mundo empresarial, por isso é preciso gerenciá-lo.

A gestão do conhecimento busca alavancar a eficácia organizacional, usando elementos comportamentais tantos dos indivíduos, quanto em grupos, e de elementos na estrutura da própria organização e das tecnologias de informação (Chan \& Lee, 2007). Embora, essa gestão seja nesse sentido um recurso estratégico, boa parte das empresas ainda não põe em prática a gestão do conhecimento, normalmente por não crer na utilidade da mesma, por não encontrar formas de implementá-las ou até mesmo por desconhecê-la (Nowacki \& Bachnik, 2016).

Visto que o novo conhecimento sempre parte do indivíduo, e é a partir de então que se pode transformá-lo em conhecimento organizacional (Takeuchi \& Nonaka, 2008), as organizações possuem nos colaboradores o insumo inteligência e conhecimento tácito para transformar suas ações e obter as vantagens competitivas desejadas. Sendo assim, a Gestão de Pessoas também um desse processo.

Partindo desse ponto, percebe-se que é o indivíduo quem desempenha a função principal de fornecer o insumo conhecimento e de ser ativo nas interações de compartilhamento do mesmo. As Tecnologias da Informação - TI surgem como meios para se obter, difundir, compartilhar e criar conhecimento, a Internet e Tecnologia de Informação e Conhecimento - TICs, por exemplo, são excelentes instrumentos para viabilizar a aprendizagem (Gozzi, 2012).

Uma área que vez mais, depende de seus serviços apoiados em conhecimento e tecnologias é a área de agências de viagens, que funciona como canal de distribuição de serviços turísticos: planeja, organiza e coordena viagens e ainda exerce função de operadora para outras agências (Petrocchi \& Bona, 2003). Para realizar essas funções, torna-se essencial o gerenciamento de informações somado a conhecimento amplo dos colaboradores e a imersão direta nas ferramentas e equipamentos disponíveis pela TICs.
Elencado esses fatores, pretende-se observar como é feito o processo de conversão de conhecimento em uma agência de viagens, tendo a TI como intermediária dos processos. Assim, o universo da presente pesquisa é uma franquia de agência de viagens, filial de Natal, que constitui-se de uma franquia de agências de viagens totalmente virtual, exigindo dos funcionários $o$ trabalho constante apoiado na Tecnologia.

Portanto, o trabalho tem como objetivo analisar como ocorrem as conversões de conhecimento em uma franquia de agências de viagens em Natal/RN, por meio das Tecnologias da Informação, tomando como base o modelo de conversões da Espiral do conhecimento de Takeuchi e Nonaka.

O trabalho traz primeiramente uma visão geral da relação entre a Gestão Estratégica de Pessoas e a Gestão do Conhecimento, ressaltando sua importância e atuação para o mercado atual, bem como o conhecimento dentro das organizações e seus processos de conversões. Posteriormente, como o conhecimento e as tecnologias mudaram a configuração dentro do mercado de agências de viagens, e por fim, a análise do caso estudado neste trabalho.

\section{CONSIDERAÇÕES SOBRE GESTÃO ESTRATÉGICA DE PESSOAS E GESTÃO DO CONHECIMENTO}

É primordial que os objetivos da gestão estratégica de pessoas estejam claros e definidos para que uma empresa consiga êxito. Um dos grandes desafios da atualidade nas instituições é desenvolver a qualidade de vida no trabalho, visando a produtividade e bem-estar social das pessoas, uma vez que é a motivação dos colaboradores que garante a qualidade das ações desenvolvidas (Sovienski \& Stigar 2008, p.58).

A gestão de pessoas no ciclo da gestão estratégica tem sido uma das etapas de extrema relevância no delineamento das ações e na implementação de práticas e políticas que norteiam uma organização, comprovando ser um dos desencadeadores da vantagem competitiva para as empresas, sendo alvo de estudos recentes tanto em âmbito nacional, quanto internacional, e fortalecendo o interesse na área pela avaliação de resultados originários da gestão de pessoas (Barreto, 2011).

O gestor de pessoas deve ter sempre uma perspectiva do que quer, ele precisa pensar o futuro, portanto faz-se necessário um planejamento estratégico que deixe os objetivos e metas bem claros. A informação hoje, transformada em conhecimento é um fator diferencial para alcançá-los. Daí a necessidade de gerir esse conhecimento para usufruí-lo da melhor maneira possível. 
A gestão do conhecimento focada nas pessoas funciona de acordo com as suas competências, suas criatividades, suas habilidades e os seus papéis gerenciais. E isso depende dos valores, das crenças e dos princípios éticos dos indivíduos que fazem parte da empresa. Dessa maneira, a gestão do conhecimento dispõe como principal aplicação a competitividade, e é sob a ótica da vantagem competitiva que devem ser feitas as avaliações dessa implantação (Texeira Filho, 2000).

Conforme destaca Drucker (1993 como citado em Nonaka \& Takeuchi, 1997), o conhecimento deixa de ser apenas um recurso ao lado dos valores econômicos, dos recursos naturais e também da mão de obra. Ele ainda afirma que a sociedade atual inseriu a inteligência das pessoas e o conhecimento nos fatores tradicionais de produção, contribuindo para a agregação de valor aos produtos e serviços. O conhecimento passou assim a ser o principal recurso.

Tendo em vista o contexto competitivo que é vivenciado pelas organizações:

A Gestão do Conhecimento é um processo estratégico contínuo e dinâmico que visa gerar o capital intangível da empresa e todos os pontos estratégicos a ele relacionados e estimular a conversão do conhecimento. Deste modo deve fazer parte da estratégia organizacional e ter sua implantação garantida e patrocinada pela alta gerência, a quem deve estar subordinado todo o processo de Gestão do Conhecimento. (Rossato, 2006, p.10).

É evidente assim, o papel da gerência nesse processo, primordialmente por sua constante intervenção para que o capital intelectual da empresa possa ser administrado da melhor forma possível.

Visto que o conhecimento é um elemento diferencial para as empresas, não se pode desconsiderar que existem divergências nas próprias organizações em relação aos investimentos em conhecimento, já que para muitos gestores é difícil perceber "os benefícios práticos do mapeamento do conhecimento sobre os processos da empresa. Mas às vezes é mais fácil perceber o custo de não ter este conhecimento registrado" (Teixeira Filho, 2000, p. 77). Ou ainda que falta desconhecimento por parte das altas gerências sobre o assunto, ou mesmo que não conseguem implementá-las e visualizar utilidade para a gestão de conhecimento (Nowacki \& Bachnik, 2016).

O primeiro passo então é levar em conta o individuo, pois é ele o elemento que transforma o conhecimento organizacional (Takeuchi \& Nonaka, 2008). A partir de então deve-se levar em consideração que existem dois tipos de conhecimentos: o tácito e o explícito, o primeiro é construído pelas experiências e trocas das pessoas proporcionadas pelo ambiente que as circundam, portanto da relação do indivíduo e o mundo em que está inserido. Já o segundo, que surge do tácito, nada mais é que a materialização de um conhecimento de um indivíduo que por sua vontade transmite-o, comunica-o, repassa-o para outros a fim de serem assimilados (Figueiredo, 2005).

É preciso que se entenda então que o conhecimento tácito não é visível e explicável, é altamente pessoal e difícil de formalizar, sendo difícil de comunicar-se. Ele está enraizado nas ações, nos seus ideais, valores, na experiência corporal do indivíduo. $\mathrm{O}$ conhecimento explícito pode ser facilmente transmitido aos outros de maneira formal e sistemática, através de palavras, números, sons, e compartilhado também como dados, fórmulas científicas, recursos visuais, arquivos de áudio, especificações de produtos ou manuais (Takeuchi \& Nonaka, 2008).

Esses tipos de conhecimentos dentro de uma empresa contribuem diretamente, por exemplo, no treinamento de pessoal, no feedback a um cliente no pósvenda, no aprendizado na prática de novas funções, nas negociações com parceiros, entre várias outras situações empresariais, relevando assim o quanto conhecimento é primordial para uma organização.

$\mathrm{Na}$ epistemologia ocidental sobre conhecimento, o que prevalece como o tipo de conhecimento mais verdadeiro e importante é o tácito, sendo que na epistemologia oriental, a ênfase é no explícito. Nonaka e Takeuchi propuseram um modelo de processos de conversão do conhecimento, chamado de Espiral do Conhecimento. Nesta proposta, tanto o conhecimento tácito quanto o explícito são vistos como entidades mutuamente complementares e a criação do conhecimento está ancorada no pressuposto crítico de que o conhecimento humano é criado e expandido através da interação social entre estes dois tipos de conhecimento (Takeuchi \& Nonaka, 2008).

Portanto, a partir desse modelo, é mais provável conseguir mensurar o alcance do conhecimento em seus processos de conversão, que são: Socialização, Externalização, Combinação e Internalização, processos esses detalhados assim:

A. Socialização: é o processo do compartilhamento das experiências, ele pode ser transmitido sem a necessidade da comunicação falada, é possível entender que um indivíduo é capaz de adquirir um conhecimento do outro através de observações, práticas e imitações. Dentro das organizações, um exemplo de socialização está nos treinamentos (Takeuchi \& Nonaka, 2008).

B. Externalização: é o processo de trazer a exposição de conhecimentos por meio da linguagem principalmente, transformando algo abstrato em conceitos, hipóteses, analogias, modelos. Este processo pressupõe diálogo e reflexão para a conversão de conhecimento. Como exemplo dessa conversão tem-se a interpretação de uma imagem, no contexto organizacional, slogans, marcas e logotipos podem refletir esse processo (Takeuchi \& Nonaka, 2008). 
C. Combinação: é o processo que propõe a troca de informações, as combinações que provocam sínteses. Em outros termos, há uma sistematização do conhecimento. Essas trocas são observadas na educação formal, ou os cursos de MBA. Já na área empresarial, se pode citar a ação dos administradores intermediários que por redes de informações codificadas criam conceitos de produtos e conceitos de negócios. Em um âmbito mais alto de administração, consideram-se os conceitos de visão corporativa (Takeuchi \& Nonaka, 2008).

D. Internalização: é o processo que se caracteriza por aprender na prática, as conversões de Socialização, Externalização e Combinação se tornam conhecimentos tácitos do indivíduo e a partir de então essa conversão tem êxito, gerando outros conhecimentos observando a subjetividade de cada sujeito. Dentro das organizações, o ato de verbalizar ou diagramar é muito eficiente (Takeuchi \& Nonaka, 2008).

Existem também condições para a promoção da espiral de conhecimento, a saber: intenção; autonomia; flutuação ou caos criativo; redundância e o requisito variedade. A intenção baseia-se nas formas de estratégia da organização para se chegar a uma visão de um tipo de conhecimento.

A autonomia é baseada no princípio de que qualquer membro de uma organização, no nível individual tem permissão para agir autonomamente. Depois, existem a flutuação e caos criativo, onde a primeira é uma decomposição de rotinas que desencadeiam a segunda que é o enfrentamento de crises, para ao fim, favorecerem o compromisso dos indivíduos.

A redundância é a existência de informações além das exigências operacionais imediatas dos membros e serve para se sobrepor em atividades de negócios. Para o requisito variedade ocorrer é preciso que haja o maior número de informações para os membros da organização no menor intervalo de tempo ou de passos a serem dados (Takeuchi \& Nonaka, 2008).

O Modelo da Espiral do Conhecimento servirá de base para a avaliação do conhecimento organizacional da pesquisa proposta, pois Probst, Raub e Romhardt (2002) falam que quantificar o conhecimento pode parecer uma tarefa impossível, mas há como registrá-lo indiretamente facilitando a aproximação da realidade.

\section{CONHECIMENTO E TECNOLOGIA NO CENÁRIO DAS AGÊNCIAS DE VIAGENS}

Atualmente, as empresas têm feito grande uso da tecnologia da informação como instrumento

4 São compras feitas na internet motivadas pela conveniência comercial de fazê-las em casa, economizar tempo, exigir menos esforços, maior flexibilidade, e gerencial, nos mais diversos ativos físicos da empresa, com a finalidade de economia de tempo e dinheiro. Nos tempos atuais, o que determina o sucesso ou fracasso de uma empresa está intimamente ligado à administração do conhecimento, seja nos processos utilizados, dados, habilidade dos funcionários, conhecimento dos clientes, fazendo uso intensivo de máquinas e computadores, etc. (Cruz et al., 2011).

É assim que o desenvolvimento das tecnologias da informação (TI) tem um grande efeito na operação, na estrutura e na estratégia das empresas de turismo no mundo: diminui-se com as novas tecnologias os custos de comunicação e operação, aumentando a interatividade, a eficiência, produtividade e competitividade. Cooper (2003, p. 458) salienta que "a competitividade, tanto das empresas quanto das destinações, está sendo redefinida, uma vez que eles maximizam a utilização, o desenvolvimento e a aplicação dessas tecnologias".

As tecnologias de informação para as agências de turismo atualmente são fortes aliadas, pois fornecem informações instantâneas, estruturas completas para reservas e emissões e apoiam a intermediação entre consumidores e agentes.

O cenário antes das TIs no mercado de agências de viagens era um ambiente competitivo morno, onde as agências faziam poucos esforços para se manter no mercado, já que as comissões dos serviços turísticos (hotéis e companhias aéreas, principalmente) eram altamente lucrativas e pouco era preciso fazer para atrair clientes, já que as agências exercia o papel de intermediar esses serviços. Com o surgimento das TIs diretamente usadas no mercado de serviços turísticos, as agências de viagens perderam sua exclusividade de intermediadoras, pois as tecnologias mudaram o contexto dos canais de distribuição, impactando assim fortemente nas comissões, vendas e lucros das mesmas. Assim, muitas agências decretaram falência e outras se reposicionaram no mercado, usando as ferramentas das Tecnologias a seu favor, muitas delas aderindo ao ecommerce $^{4}$, e ao uso de Global Distribution System GDS como um fator que melhora o sistema de distribuição, tornando os bancos de dados mais completos e otimizando os serviços (Marín, 2004; Tomelin, 2001; Cooper, 2003).

Daí segue-se uma junção entre as tecnologias disponíveis ao conhecimento individual dos colaboradores, tornando as agências convencionais agora em consultorias de viagens, onde a internet é uma das principais fontes de informações. E os clientes, por sua vez, são mais exigentes e participativos na montagem de suas viagens (Moraes, 2007). Para controlar esses processos, ter mais informações, dar garantias aos clientes e diversificar serviços é necessário

preços mais baixos (Chaparro-Peláez; Agudo-Peregrina; Pascual-Miguel, 2016). 
a habilidade de transformar conhecimento (Quevedo, 2007).

Por consequência, o conhecimento é primordial na gestão de uma agência de viagens no contexto atual do mundo globalizado e da sociedade imersa em uma rede, tendo a informação como principal ingrediente econômico (Castells, 1999). O agenciamento turístico claramente não está aquém dessa realidade e a questão se volta para como o fator tecnologia está sendo mesclado ao conhecimento e sua gestão.

\section{METODOLOGIA}

A presente pesquisa é um estudo descritivo, com adoção do método de estudo de caso, aplicado na filial de Natal no Rio Grande do Norte de uma franquia de agência de viagens. A empresa atua no mercado há dez anos, com os serviços de agenciamento turístico e há mais de cinco anos em seu modelo de franquia, oferecendo suporte de orientação, apoio logístico e operacional no segmento. A filial da franquia pesquisada, no caso, constitui uma loja que, além de fazer a consultoria presencial aos clientes, faz uso de toda a tecnologia, que é o ponto forte da marca, usandose do sistema interno de informações da rede.

$\mathrm{O}$ estudo foi feito mediante a aplicação de um questionário de perguntas abertas aos funcionários da agência de viagens pesquisada, com o intuito de identificar os processos de conversão do conhecimento que ocorrem na empresa por intermédio da Tecnologia de Informação que estão disponíveis para o trabalho nesta organização. O levantamento de dados foi feito in loco com a colaboração dos funcionários da empresa que se dispuseram a responder ao questionário desenvolvido para a pesquisa.

$\mathrm{O}$ instrumento de pesquisa foi tecido com bases nos quatro processos de conversão de conhecimento detalhados no Modelo de Espiral do Conhecimento de Takeuchi e Nonaka (2008). Ele é composto de dez questões mesclando as conversões de conhecimento com as TI's, como ilustra o Quadro 1 abaixo:

\section{Quadro 1 - Questionário para análise das TI's na Espiral do Conhecimento}

\begin{tabular}{|c|c|}
\hline $\begin{array}{l}\text { Conversão do } \\
\text { Conhecimento }\end{array}$ & QUESTÕES \\
\hline Socialização & $\begin{array}{l}\text { 1. Quando você precisa de novas informações sobre o trabalho, onde você a procura? O } \\
\text { sistema interno na empresa é útil para essa finalidade? } \\
\text { 2. É possível observar a prática dos colegas de trabalho para aplicação de suas tarefas? } \\
\text { 3. Você observa as considerações dos clientes para aplicação na agência? Algumas dessas } \\
\text { observações são feitas em canais eletrônicos? }\end{array}$ \\
\hline Externalização & $\begin{array}{l}\text { 4. Existem meios de comunicação tecnológicos internos para a exposição de ideias e novos } \\
\text { conteúdos por parte do colaborador? Se sim, como são usados? } \\
\text { 5. Quanto às normas e manuais de trabalho, você acessa constantemente estes } \\
\text { documentos? Eles estão disponíveis on line com acesso livre ou em algum meio digital? } \\
\text { 6. Qual seu posicionamento em relação a esses manuais quanto a sua efetividade e } \\
\text { clareza? }\end{array}$ \\
\hline Combinação & $\begin{array}{l}\text { 7. São realizados reuniões ou eventos constantes na empresa? E em algum deles são } \\
\text { usados vídeo ou teleconferência? Você costuma participar ativamente com ideias e } \\
\text { proposições nessas ocasiões? } \\
\text { 8. É possível que você tenha acesso as informações pertinentes a todos os setores pelo } \\
\text { sistema interno da empresa? }\end{array}$ \\
\hline Internalização & $\begin{array}{l}\text { 9. Como você costuma analisar suas vivências na prática do trabalho e de seus colegas da } \\
\text { agência? O sistema interno permite a inserção de dados de experiências vividas no } \\
\text { trabalho para uso posterior? } \\
\text { 10. É usual você desenvolver tarefas que teve que aprender na prática? E em relação aos } \\
\text { sistemas e meios tecnológicos que a empresa faz uso? }\end{array}$ \\
\hline
\end{tabular}

Fonte: Elaboração própria (2013)

A análise dos dados foi realizada por meio da técnica de análise de conteúdo, visto que a mesma é considerada importante nas contribuições que oferecem às pesquisas em Ciências Sociais Aplicadas (Moraes, 1998). Ainda porque, consiste em uma técnica que busca caracterizar um discurso de maneira sistemática, sendo muito mais um método de observação do que análise (Espírito Santo, 1992). Assim, a partir das respostas dos questionários buscou-se extrair as interações entre as tecnologias da informação e o processo de gestão do conhecimento. 


\section{A GESTÃO DO CONHECIMENTO NA AGÊNCIA DE VIAGENS PESQUISADA}

A empresa onde foi feita a aplicação dos questionários baseados no Modelo da Espiral do Conhecimento surgiu em 2003 com a ideia de oferecer serviços exclusivos e diferenciados dos que já existem no segmento de viagens e turismo. No final de 2008, deu-se início ao projeto de expansão da empresa, onde o formato de franquia foi responsável pela evolução da empresa. Em Janeiro de 2009, a empresa passou a negociar e comercializar unidades franqueadas por todo o território nacional.

A empresa desenvolve modalidades de franquias, sendo elas: "Home Office voltada para vendas on-line", sem necessidade de loja física; "Corporativo", que é voltada para atender empresas e seus funcionários; "Quiosque", que são franquias autônomas instaladas em shopping centers ou supermercados; "Loja", que consiste em uma agência comum com espaço físico; "Franquia máster", que funciona como parceira da matriz em João Pessoa na Paraíba, por participar da captação de novos franqueados e participar das comissões. A franquia pesquisada é da modalidade "Loja".

\section{Análise das Etapas da Espiral do Conhecimento}

Segue a análise observando a sequência das conversões de conhecimento da Espiral do modelo de Takeuchi e Nonaka na agência de viagens pesquisada.

\section{A. Socialização:}

Quando indagados sobre a fonte de consulta de novas informações pertinentes ao trabalho e a utilização para tal pelo sistema interno da empresa, foi unânime a consideração de que o portal da franquia e o e-mail são fontes primordiais. Entretanto, o sistema é considerado difícil de manusear e em relação a tirar dúvidas, o sistema não oferece muitas opções de interação.

Mezghani, Exposito e Drira (2016) que apontam para significativos avanços na Gestão do Conhecimento com base na T.I. se tornaram um meio importante para aumentar a produtividade e atingir a eficácia da equipe, afinal, a tecnologia oferece métodos e ferramentas que capturam, compartilham e facilitam o acesso ao conhecimento, que é o caso dos sujeitos aqui investigados, que fazem uso constante dessas ferramentas.

No entanto, não pode- deixar de considerar a afirmação dos colaboradores quanto ao difícil manuseio do sistema e sua pouca disponibilidade de ajuda, que pode consequentemente ser um ponto negativo na absorção e transferência de conhecimento por parte dos funcionários, visto a colocação de Zahra e George (2002 como citado em Calvo-Mora, Navarro-García \&
Periañez-Cristobal, 2015) onde se o principal objetivo da Gestão do Conhecimento é gerar valor para os agentes e a transferência e aplicação desse conhecimento deve ser feita de maneira eficiente, caso contrário, apresenta-se um aspecto crítico nas organizações que deve ser revisto.

Outro canal de geração de conhecimento na empresa pesquisada são os fornecedores diretos e indiretos da empresa, como operadoras de turismo, agências de receptivo, companhias aéreas, hotéis, agências de câmbio que fazem o papel de informantes sempre comprometidos com a comunicação, fornecendo informações atualizadas sobre seus produtos, sobre o mercado em geral, oportunidade de negócios e até mesmo de seus parceiros, promovendo assim novas parcerias e fortalecimento da que já existe. Essa comunicação é feita por e-mails, telefonemas ou até mesmo através de visitas à agência.

Observando que são mantidas as chaves de elucidação, capturação e compartilhamento de conhecimento, levantadas por Mezghani, Exposito e Drira (2016) que são as interações pessoais, como entrevistas, brainstorming, reuniões, etc. pois elas são as principais formas de fonte de conhecimento apontadas pelos especialistas da área.

Em relação à observação da prática dos colegas de trabalho, foi ressalvado o fato de a empresa ter poucos funcionários facilitar a comunicação interna entre eles, observando dicas ou informações exclusivas, além do uso futuro de informações com clientes. Sobre as considerações feitas pelos clientes da agência e as opções que os mesmos têm de fazê-las por canais eletrônicos, foi constatado que a maioria esmagadora das reclamações e sugestões são feitas pessoalmente, embora haja a opção do canal eletrônico, e ainda as colocações são levadas em consideração na melhoria do serviço da empresa. Como sugerem Takeuchi e Nonaka (2008), o modo de socialização constrói um campo de interação que facilita compartilhar as experiências e modelos mentais de cada indivíduo.

\section{B. Externalização:}

Primeiramente foi revelado que não há meios de comunicação tecnológica interno para que os colaboradores possam expor novas ideias para a empresa ou mesmo compartilhar experiências através de arquivamentos no sistema. As ideias são compartilhadas através do diálogo, de maneira natural no dia-a-dia de trabalho.

Esta colocação revela uma realidade muito comum no campo das empresas que não fazem uma gestão dos seus recursos de conhecimento. Nowacki e Bachnik (2016) citam as razões para essa falta de gestão sobre o conhecimento, são elas: a descrença na utilidade desta gestão; a visão de que não há como implementar as práticas de gestão de conhecimento; e ainda, a alta estão das empresas desconhecem sobre o assunto. 
Outro dado que atenua a falta de gestão do conhecimento aplicada de maneira mais efetiva é sobre às normas e manuais da empresa, onde existe apenas o manual de utilização do portal e vendas de passagens, que é considerado pelos pesquisados como simples, muito básico e sem aprofundamento em relação a informações relevantes para o trabalho em si.

Os sujeitos da pesquisa afirmaram que as ideias que são compartilhadas são voltadas para ações de marketing, mudança na estrutura física ou na forma de atuação da empresa diante dos clientes. Corroborando para o fato de a externalização ser proveniente da reflexão coletiva significativa, onde metáforas e analogias auxiliam na compreensão de conhecimentos tácitos ocultos (Takeuchi \& Nonaka, 2008). Neste caso, especificamente para as ações de marketing, há uma síntese de ideias para se chegar a uma definição comum.

\section{Combinação:}

Em relação a reuniões e eventos na empresa, principalmente com uso de tecnologias, foi informado que não existem reuniões nesta filial com constância. As reuniões e decisões ocorrem na matriz, onde frequentemente eles são convidados a participar, porém presencialmente, fato que dificulta porque cada franqueado deve arcar com os custos da viagem de seus colaboradores.

Vale lembrar que a Combinação surge pela rede de conhecimento criada recentemente na organização ou que provém do conhecimento já existente de outras seções de organização (Nonaka \& Takeuchi, 1997). Portanto, a dificuldade que muitos franqueados enfrentam de custear as viagens dos colaboradores, sugere que pode haver quebras na rede de conhecimento da empresa, já que as reuniões são um ponto chave no repasse dos conhecimentos internos.

Por ser rara a participação da maioria dos entrevistados em reuniões ou outras formas de contato mais efetiva com a gerência da matriz, considera-se que a flutuação e caos criativo na empresa fica dispersa, já que esta condição é induzida pela alta gerência.

No que diz respeito às informações pertinentes a todos os setores, os entrevistados afirmaram que é possível saber todos os acontecimentos da organização através do sistema interno. No entanto, sobre os setores o acesso completo de todas as informações é apenas do setor comercial, fato que pode dificultar a transferência de know-how coletivo, já que este é mais difícil de circular e de transferir, e, quanto mais ele é constituído por prática de trabalho, menos relevante é a ausência de um ou de alguns dos membros dessa "coletividade" (Oliveira Jr., Fleury \& Child, 2010, p. 297). Considerase que se há a criação desse know-how coletivo, a própria saída de funcionários e entrada de funcionários novos, não influenciará com impacto muito forte na manutenção do conhecimento.

\section{Internalização:}

As vivências da prática de trabalho e a inserção de dados sobre essas experiências não são permitidas para alocação no sistema interno da empresa. Em relação a tarefas que aprendem na prática e como os meios tecnológicos contribuem nessa questão, é unânime que os sistemas quanto mais usados, mais provêm novas informações para o trabalho.

A internet, por exemplo, grande representante da sociedade informacional, segundo os entrevistados oferece grande contribuição no auxílio dos agentes. Treinamentos oferecidos pelas operadoras, que não é exclusivo da franquia, são também fonte de conhecimento mútuo para todos. O requisito variedade é bem enfatizado nesse sentido, por ter a evidência de sua principal característica, a rapidez da passagem de informações.

Nowacki e Bachnik (2016) falam sobre as inovações na gestão do conhecimento dentro das empresas e os autores destacam que as inovações tecnológicas costumam ganhar mais margem do que as inovações sociais, sendo $29,6 \%$ e $27,4 \%$ respectivamente. A ênfase em inovações tecnológicas é proveniente da crença de que a infraestrutura tecnológica é prioridade nos dias atuais. Os mesmos autores ainda afirmam que a tendência é mais forte entre empresas de médio porte, fabricantes e empresas de serviços, que este último, é o caso de nossa empresa, objeto de pesquisa.

Assim, o aprender na prática é ainda muito pertinente e é altamente auxiliado pelas tecnologias que os colaboradores têm acesso, já que treinamentos só ocorrem em fase inicial na empresa, ressaltando a importância da internalização que vem do aprender fazendo (Takeuchi \& Nonaka, 2008). Quando ocorrem erros, todos são informados e procuram solucioná-los, visto que há uma propensão ao erro na atividade, segundo os entrevistados, seja pela complexidade dos sistemas ou pela grande quantidade de informações que devem absorver para utilizá-las no dia a dia. Se necessário, eles recorrem a profissionais externos à empresa, pois o mercado de viagens não permite a correção de erros sem perdas de valores.

Assim, a redundância ocorre com mais clareza na empresa, e o aprender na prática enfatizado anteriormente, adicionado ao uso de tecnologias são visíveis nesta condição, e se observa ainda a procura pelo aprimoramento do conhecimento. Já a autonomia ainda é tímida, pelo menos no que diz respeito à filial pesquisada, pois foi observada a existência de uma concentração nas tomadas de decisões, mesmo as mais simples. 


\section{Discussão dos Resultados da Espiral do Conhecimento}

Pelas análises das condições de promoção da espiral do conhecimento, pode-se observar em relação à intenção que, por ser uma franquia, existe na empresa todo um conjunto de normas e padrões a serem seguidos para o conceito comum da empresa e que um grande propulsor disso é o sistema interno da agência. Ele é ferramenta importante para se chegar aos objetivos e metas da empresa.

As conversões do conhecimento na agência pesquisada por intermédio das tecnologias são mais perceptíveis em algumas características que em outras. Primeiro exemplo disso é a Socialização. É muito propícia a socialização de conhecimentos na empresa porque o sistema interno é grande fonte de informação, embora com algumas dificuldades em seu manuseio, além do que o número pequeno de funcionários favorece a observação da prática do outro e cria-se um clima de confiança com o cliente, favorecendo as sugestões pessoais por parte destes.

Já a Externalização é dificultada pela impossibilidade de exposição de ideias e arquivamentos de experiências e informações sobre vivências no sistema. O máximo que acontece é a interação pessoal e troca de experiências por aqueles que convivem entre si no ambiente de trabalho. O e-mail seria uma segunda opção, porém não é usado com esta finalidade.

Concordando com Calvo-Mora, NavarroGarcía e Periañez-Cristobal (2015) a transferência de conhecimento é realizada com a informação através de meios de comunicação. Este é um método mais eficaz para disseminar o conhecimento explícito, e para grupos maiores de pessoas. Neste contexto, as T.I. existem e são usadas na etapa de Externalização, mas de maneira restrita, ficando a interação pessoal como o ponto principal.

Quanto à Combinação, a informação de que o sistema não permite a inserção de ideias, somado ao fato de as reuniões serem realizadas com maior frequência na matriz e exige que os colaboradores viajem, fato que raramente ocorre, reverbera na eminente dificuldade de síntese de conceitos por parte dos colaboradores, que poderiam ser úteis no serviço prestado na empresa.

A colaboração e participação humana é necessária para sustentar uma transferência de conhecimentos eficiente e partilhada. Mesmo assim, alguns fatores culturais e sociais podem impedir o progresso desta gestão (Mezghani, Exposito \& Drira, 2016). Na organização pesquisada, o fator deslocamento e viagens é que supostamente impedem o progresso efetivo.

A Internalização, ponto de chegada e de reinicio da espiral, é constantemente presente no dia-adia dos colaboradores da agência, pois o aprender fazendo é fundamental, seja no lidar com o próprio sistema interno que apresenta suas dificuldades de manuseio, seja no atendimento ao cliente, onde o uso de tecnologias é preponderante para o êxito nas vendas. Assim, a prática das funções é responsável por um diferencial até dos funcionários que aprimoram suas habilidades e conhecimentos.

$\mathrm{O}$ fato de haver poucos funcionários facilita a interação entre eles e, segundo Nonaka e Takeuchi (1997), o agente principal na criação do conhecimento é a interação dos funcionários de diversos níveis, pois não há uma geração de conhecimento de forma individualizada.

A Espiral do conhecimento é a interação do conhecimento tácito e explícito e tende a se tornar maior à medida que sobem os níveis ontológicos, ou seja, as interações naturais. Portanto, espiralado de um nível primário individual e chegando a coletividade pela interação, se expandindo pela organização, ultrapassando limites de departamentos, divisões e mesmo da própria organização (Takeuchi \& Nonaka, 2008).

\section{CONSIDERAÇÕES FINAIS}

Dois grandes elementos que se constituem como vantagens competitivas dentro da sociedade informacional são o conhecimento e as tecnologias de informação. O primeiro, que essencialmente necessita de indivíduos para que seja compartilhado e apreendido, encontra na segunda, uma ótima ferramenta para espalhar-se. No agenciamento turístico, estes dois elementos estão intimamente ligados.

As empresas, seja no ramo turístico ou em qualquer outro, ainda possuem falhas nas suas gestões, muitas vezes por falta de profissionais qualificados, outras por falta de informações, onde ambas recaem no conhecimento organizacional que por vezes é falho, observando a estrutura da empresa e os mecanismos dispostos nela para que o mesmo seja contínuo e dinâmico.

Com o caso da agência de viagens pesquisada, pôde-se constatar que as tecnologias não são mais secundárias no setor de agências de viagens em todos os quesitos, devido a demanda atual de mercado que exige novos serviços. Assim, a ferramenta de TI mais utilizada é sem dúvida a internet, pela instantaneidade e diversidade de informações. Outro recurso de TI amplamente utilizado é o sistema interno da empresa, já que a empresa é uma franquia e precisa ter constantes informações da rede.

As conversões de conhecimento explicadas na Espiral do Conhecimento na agência de viagens pesquisada são diretamente influenciadas por estas ferramentas de TI citadas acima, já que a grande maioria das informações gerenciais são passadas por meios tecnológicos, a prestação do serviço e as fontes de novas informações. 
Deste modo, as tecnologias são grandes facilitadoras dos processos de conversão da espiral do conhecimento, sendo que na empresa estudada, os processos de Socialização e Internalização são acentuadamente mais facilitados pelas Tecnologias de Informação que os processos de Combinação e Externalização. Por outro lado, os meios de comunicação mais tradicionais, reconhecidos como principais no processo de compartilhamento de conhecimento ainda são notórios.

Este trabalho sinaliza como as ferramentas de TI exercem significância em organizações no cenário atual do mercado de agências e na facilitação de propagação de conhecimento dentro de uma empresa. $\mathrm{O}$ Modelo de Espiral do Conhecimento permitiu que se pudesse visualizar com mais clareza como ocorrem os processos de troca de conhecimento entre indivíduos através de tecnologias. Esta pesquisa trata-se de um estudo de caso em uma empresa de um segmento específico do turismo, as agências de viagens, porém sugere-se a realização de futuras pesquisas em empresas de outros ramos de mercado, que possam contribuir com a síntese e formação de conhecimento sobre a aplicação da TI dentro da Gestão do Conhecimento e seus processos.

\section{REFERÊNCIAS}

Barreto, L. M. T. S. (2011). Estratégias de gestão de pessoas e desempenho organizacional na hotelaria: o papel das capacidades organizacionais. Tese de Doutorado, Universidade de São Paulo, São Paulo, SP, Brasil.

Calvo-Mora, A., Navarro-García, A., \& PeriañezCristobal. (2015) Project to improve knowledge management and key business results through the EFQM excellence model. International Journal of Project Management, 33(8), 1638-1651.

Castells, M. (1999). A sociedade em rede. São Paulo: Paz e Terra.

Chan, Y., \& Lee, S. (2007) Capabilities, processes, and performance of knowledge management: a structural approach. Human Factors and Ergonomics in Manufacturing, 17(1), 21-41.

Chaparro-Peláez, J., Agudo-Peregrina, A. F., \& Pascual-Miguel, F. J. (2016) Conjoint analysis of drivers and inhibitors of e-commerce adoption. Journal of Business Research, 69(4), 1277-1282.

Cooper, C. (2003). Turismo: princípios e prática. (2a ed.) Porto Alegre, Bookman,
Cruz, J. A. W. (2011). Construção de indicadores de mensuração do capital Intelectual em uma empresa brasileira de consórcios. Revista Gestão Industrial, 7(1), $92-106$.

Espírito Santo, A. (1992). Delineamentos de Metodologia científica. São Paulo: Loyola.

Figueiredo, S. P. (2005) Gestão do Conhecimento: estratégias competitivas para a criação e mobilização do conhecimento na empresa. Rio de Janeiro: Qualitymark,

Franzoni, A. M. B. (2007). Era do conhecimento: O novo perfil do profissional de turismo. In: Quevedo, Mariana (Org.). Turismo na era do conhecimento. Florianópolis: Pandion.

Gozzi, M. P. (2012) O processo de gestão do conhecimento em comunidades virtuais de aprendizagem. Perspectivas em Gestão \& Conhecimento, 2(2), 3-14.

Marín, A. (2004). Tecnologia da informação nas agências de viagens: em busca da produtividade e do valor agregado. São Paulo: Aleph.

Mezghani, E, Exposito, E, \& Drira, K. (2016) A collaborative methodology for tacit knowledge management: Application to scientific research. Future Generation Computer Systems, 54, 450-455.

Moraes, R. (1998). Uma experiência de pesquisa coletiva: Introdução à Análise do conteúdo. In: Grillo, M. C., \& Medeiros, M. F (Orgs.) A construção do conhecimento e sua mediação metodológica. Porto Alegre: EDIPURCS.

Moraes, A. G. (2007). Tecnologia de informação nas agências de turismo: uma análise de como as agencias estão utilizando esse recurso para se manter competitiva. Revista de Turismo y Patrimonio Cultural, 5(2), 163-173.

Nowacki, R., \& Bachnik, K. (2016) Innovations within knowledge management. Journal of Business Research, 69(5), 1577-1581.

Nonaka, I., \& Takeuchi, H. (1997). Criação de conhecimento na empresa. Rio de Janeiro: Campus.

Oliveira Jr., M. M., Fleury, M. T. L., \& Child, J. (2010). Compartilhando conhecimento em negócios internacionais: Um estudo de caso na indústria da propaganda. In: Fleury; M.T.L., \& Oliveira Jr., M. M. (Orgs.) Gestão estratégica do conhecimento: integrando aprendizagem, conhecimento $e$ competências. São Paulo: Atlas. 
Petrocchi, M., \& Bona, A. (2003). Agências de Turismo: planejamento e gestão. São Paulo: Futura.

Probst, G., Raub, S., \& Romhardt, K. (2002). Gestão do Conhecimento: os elementos construtivos do sucesso. Porto Alegre: Bookman.

Quevedo, M. (2007). Os impactos das tecnologias de informação e comunicação no turismo. In: Quevedo, M. (Org.). Turismo na era do conhecimento. Florianópolis: Pandion.

Sovienski, F., \& Stigar, R. (2008). Recursos Humanos X Gestão de Pessoas. Gestão: Revista Científica de Administração e Sistemas de Informação, 10(10), 51-61.

Takeuchi, H., \& Nonaka, I. (2008). Gestão do conhecimento. Porto Alegre: Bookman.

Teixeira Filho, J. (2000). Gerenciando conhecimento. Rio de Janeiro: SENAC.

Tomelim, C. A. (2001). Mercado de Agências de Viagens e Turismo: como competir diante das novas tecnologias: São Paulo: Aleph. 